\title{
A "mental models" approach to the communication of subsurface hydrology and hazards
}

\author{
Hazel Gibson $^{1}$, Iain S. Stewart ${ }^{1}$, Sabine Pahl ${ }^{2}$, and Alison Stokes ${ }^{1}$ \\ ${ }^{1}$ School of Geography, Earth and Environmental Sciences, Plymouth University, Plymouth, UK \\ ${ }^{2}$ School of Psychology, Plymouth University, Plymouth, UK \\ Correspondence to: Hazel Gibson (hazel.gibson@ plymouth.ac.uk)
}

Received: 16 December 2015 - Published in Hydrol. Earth Syst. Sci. Discuss.: 18 January 2016

Revised: 12 April 2016 - Accepted: 15 April 2016 - Published: 4 May 2016

\begin{abstract}
Communicating information about geological and hydrological hazards relies on appropriately worded communications targeted at the needs of the audience. But what are these needs, and how does the geoscientist discern them? This paper adopts a psychological "mental models" approach to assess the public perception of the geological subsurface, presenting the results of attitudinal studies and surveys in three communities in the south-west of England. The findings reveal important preconceptions and misconceptions regarding the impact of hydrological systems and hazards on the geological subsurface, notably in terms of the persistent conceptualisation of underground rivers and the inferred relations between flooding and human activity. The study demonstrates how such mental models can provide geoscientists with empirical, detailed and generalised data of perceptions surrounding an issue, as well reveal unexpected outliers in perception that they may not have considered relevant, but which nevertheless may locally influence communication. Using this approach, geoscientists can develop information messages that more directly engage local concerns and create open engagement pathways based on dialogue, which in turn allow both geoscience "experts" and local "non-experts" to come together and understand each other more effectively.
\end{abstract}

\section{Introduction}

Communicating information about geological and hydrological hazards relies on appropriately worded communications (Liverman, 2010) targeted at the needs of the audience (Nisbet, 2009). Those needs are often deemed to be what geoscience professionals feel the public "need to know", lead- ing many hazard messages to fall into the largely nowrejected "deficit model" of communication (Sturgis and Allum, 2004). That model assumes people need to be educated about those areas of knowledge in which they are seen to be deficient, and it ignores their existing knowledge structures and wider concerns or values. Moreover, the responsibility for tailoring the communication to the target audience is often placed on the public, requiring them to "ask the right questions" (Rosenbaum and Culshaw, 2003). This emphasis on the public's requirement to ask the right questions misses a bigger issue in communicating geological hazards, namely the influence of intuitive judgments, such as heuristics (Gilovich et al., 2002), in how people may interpret information, especially unfamiliar scientific and technical data (Kunreuther and Slovic, 1996).

The value in examining perceptions specifically is increasingly being recognised by many in the risk communication community, including in disaster risk reduction and commercial geology fields. Barclay et al. (2008), for example, called for a more interdisciplinary "disaster reduction" approach to volcanic risk communication, which includes stakeholders in policymaking and uses social and physical science to work together to produce more appropriate and effective communications based on the needs of the community. Meeting the particular needs of at-risk communities through collaboration between the physical and social sciences is now emerging as a fairly central component of modern risk science (Donovan et al., 2012; Frewer, 2004; Lave and Lave, 1991; Mabon et al., 2014).

The subjective nature of risk communication and understanding among both experts and non-experts is now well established (Slovic et al., 2004), but it is easy for risk 
communicators to focus on improving access to information from the scientists' perspective and overlook the impact of experience- and emotion-based preconceptions from the non-expert perspective (Leiserowitz, 2006). Commonplace preconceptions will strongly influence the way that a nonspecialist will access and interpret the geoscience risk information provided to them (Liverman, 2010), and so it is vital that public perceptions of geological and hydrological hazards be taken into consideration by communicators. An example of the importance of misconceptions is provided by Shackley et al. (2004), who report a geoscience expert using the term "bubble" of $\mathrm{CO}_{2}$ (Shackley et al., 2004, p. 127) to explain carbon capture and storage to a lay audience; the result was a participant gaining a misconception relating to the storage of the carbon in the form of "a large bubble" of gas which could burst at any time. This misconception caused some participants great distress and increased their perception of the risk.

It has long been known that, when the public receive information, they can interpret it - and therefore organise their reactions - in a variety of ways depending on their perception of both the science and the scientist (Fischhoff, 1995). Various inherent cultural and social assumptions control the way that this information is interpreted, not excluding the influence of the individual's previous educational background (Donovan, 2010; Mabon et al., 2014; Slovic et al., 2007). Thus, without examining a population through social or psychological scientific inquiry, it is impossible to predict how they will respond to a particular science communication message (Wynne, 1991). An example of the impact of the participant's background on a risk communication message was explored in a study by Keller et al. (2006). It was found that a person's background and experience, particularly of previous flooding events, had a significant impact on the severity of risk ascribed to a flood hazard communication.

A key challenge of communicating such messages, therefore, is that in addition to the wider social or cultural impact on perception of scientific information, individuals apply their own pre-existing ideas and concepts to any scientific data that they are presented with (Mileti et al., 2004). In this context, psychology-based methods are vital, and one such method is the "mental models" approach (Morgan et al., 2002). This paper introduces the mental models methodology and presents empirical evidence for public perceptions of the geological subsurface, making inferences about how those perceptions relate to geological and hydrological hazards.

\section{Communicating risk via mental models}

Conventional views of risk communication have been based on how best to align the knowledge of the recipient with that of the expert (or communicator). Early work by Slovic (1987) demonstrated how several key factors under- lie the perception of risk in non-experts, notably concepts such as "familiarity" and "dread". A graphical representation (Fig. 1) shows the relative perceptions of different threats, as organised by their varying degrees of familiarity and dread. The diagram shows that certain threats which may statistically be considered more risky - such as riding a bicycle - are perceived to be far less risky than a statistically safer activity, such as flying in a commercial aeroplane (Slovic, 1987). Later work coined the term "affect heuristic" to describe the important role of intuitive feelings in non-experts' risk assessments (Slovic, 2010; Slovic et al., 2004).

The affect heuristic describes the way that an individual's perception can colour their response to a piece of information about a subject, by ascribing greater or lesser importance to the risk than an expert would, based on a logical assessment. The affect heuristic can be described as a form of emotion, defined as positive or negative feelings that are used to evaluate an external stimulus (Slovic et al., 2007). The influence of heuristics such as the affect heuristic is so central to designing effective risk communication that these need to be far more fully integrated into methods of assessing the public's perception of geological and hydrological issues (Mabon et al., 2014).

By taking into account the impact of a non-experts' perception of risk, the field of risk communication shifts from a one-way form of communication towards more of a dialogue. However, even within this more inclusive mode of communication, an outdated emphasis on the information and value judgments of the expert is still apparent (Sturgis and Allum, 2004). By this account the "top-down" transfer of information provided by the expert must be translated by the emotional state of the non-expert (Slovic et al., 2004) and integrated into their own "lay knowledge" (Callon, 1999). While experts may value local knowledge during individual communications, often the contribution of the non-expert population is dismissed as inappropriate by experts, who expect decisions to be made on the basis of relevant technical information. An example of this was found by Johnson (2008) in a study of watershed modelling and public participation, which showed that an over-reliance on technical methods for constructing the watershed model resulted in a disconnect between the public and the technical modellers, as the model was perceived to be inaccessible, despite early public enegement. There is, however, a growing acknowledgment of the role and value of individual and community knowledge, not just in collecting and compiling scientific data (Lane et al., 2011) but also in improving communications by countering the expert-imposed concept of risk (Lave and Lave, 1991). One psychological approach that has been employed effectively in communicating across a range of risky and controversial geological and hydrological issues is mental models (Lave and Lave, 1991; Maceda et al., 2009; Skarlatidou et al., 2012; Wagner, 2007; Thomas et al., 2015).

The mental models approach to communicating risk (Morgan et al., 2002) is based upon the broader mental models 


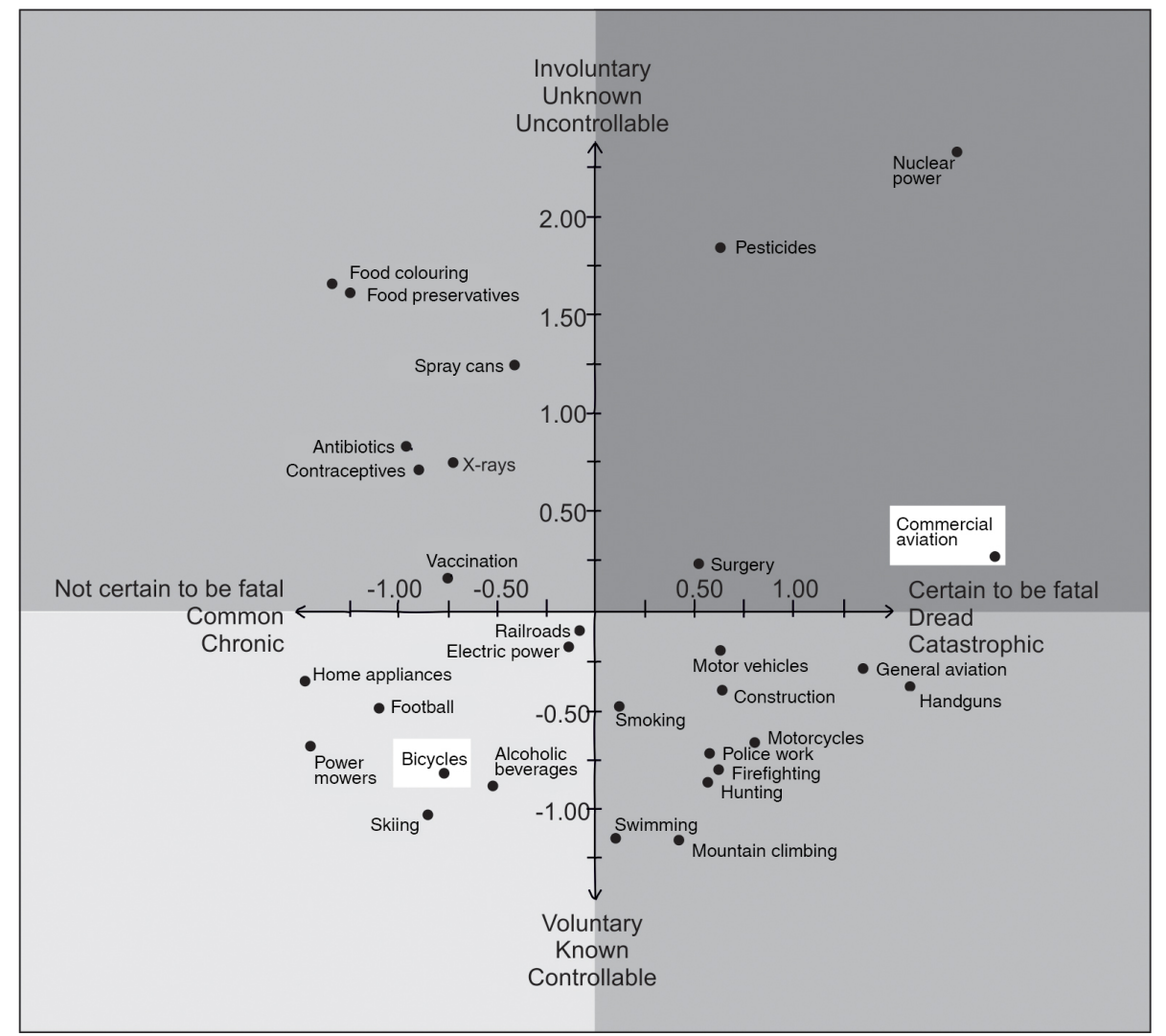

Figure 1. The perception of risk within a two-factor space, representing public perceptions of how risky an activity was based on its familiarity and how fatal the consequences may be (Slovic, 1987, p. 98).

theory, developed by Johnston-Laird (1980) as a conceptual paradigm that encompassed new ideas about language and perception in the burgeoning field of cognitive science. The theory of mental models as interpretation of theoretical reasoning has fallen from favour in psychology (Evans, 2002; Over, 2009), but it is still used in the applied sense, particularly by researchers examining decision making associated with risk, communication and education (Goel, 2007; Larson et al., 2012; Panagiotaki et al., 2009; Skarlatidou et al., 2012).

The mental models approach to risk communication employs a form of deductive reasoning, one of the multiple types of reasoning which is connected with decision making (Eysenck and Keane, 2010). The approach assumes that, in order to make a decision about an issue, an individual will construct an artificial (mental) reality in order to test a series of simulated scenarios using data previously collected and valued by that individual (Morgan et al., 2002). The decision about what action to take will be based upon a logical interpretation of the results of these tests, and decisions are most easily made when the tests are simple (Johnson-Laird, 2013).

This method can be demonstrated by considering the decision of "travelling down stairs". Whilst it may seem an exceedingly simple issue, by considering all the different fac- tors that might cause you to trip on the stairs and therefore what you may have to do to control those factors, a researcher can build a model of what a person considers when they are thinking of walking up or down stairs (Morgan et al., 2002). This simple example, represented in Fig. 2, demonstrates the particular effectiveness of mental models. In the diagram, some factors such as the floor covering, lighting or the height and width of the stairs may be anticipated by experts (for example an architectural designer, or specialist in home risk), and statistically assessed as being valuable factors to communicate hazards about. The node that mentions "sleeping habits of the cat" however may not have been considered, and yet might be a key issue for a non-expert who lives in the property in this circumstance.

The use of mental models, therefore, allows the researcher to gain a better understanding of the importance of many issues from both the expert and non-expert perspective, and it also allows for the inclusion of not just analytical reasoning but experiential reasoning as well (Leiserowitz, 2006).

In the context of geological hazards and risks, it was found that, in cases where the risks are unfamiliar to the individual, mental models theory allowed the participant to explore the decision-making process more fully (Goel, 2007). When applied to specific contexts, most notably to radioactive-waste 
(a)

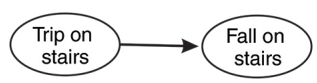

(c)

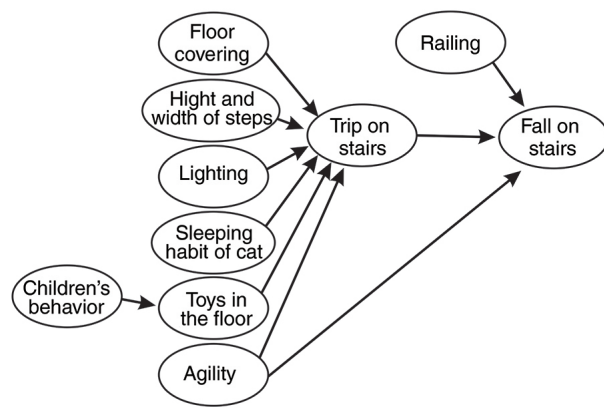

(b)

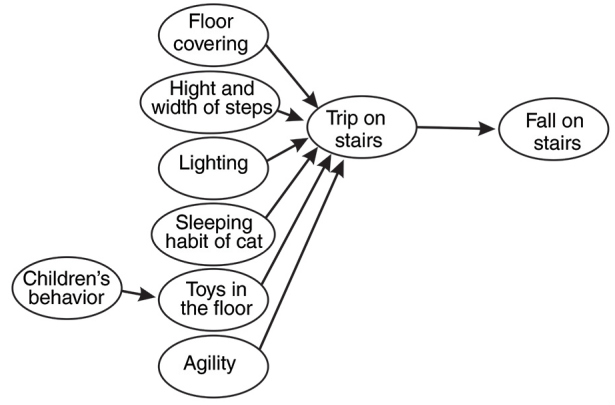

(d)

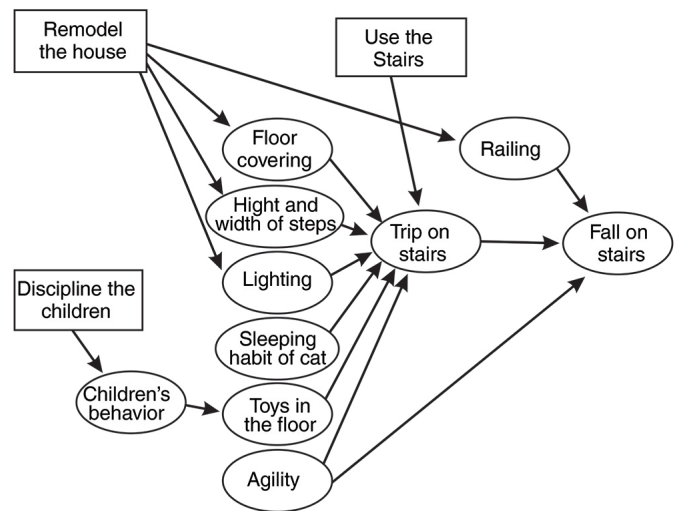

Figure 2. Illustration of the construction of an influence diagram for the risk of tripping and falling on the stairs: (a) shows just those two elements; (b) adds factors that could cause a person to trip; (c) adds factors that might prevent a fall after a person trips; and (d) introduces decisions that a person could make that would influence the probabilities of tripping and falling (Morgan et al., 2002, p. 37).

management and carbon capture and storage (Skarlatidou et al., 2012; Vari, 2004; Wallquist et al., 2010), it was found that, in cases where the perceived risk of new technology was greater than the actual risk (or the risk designated by the expert), mental models provided a useful holistic approach to decision making, which placed equal value on the attitudes of both expert and non-expert (Vari, 2004).

An important aspect of the mental models approach is in the equivalent value placed on the data coming from the nonexpert. In placing the non-expert in a position of equal authority with the expert, any information provided is also represented as being just as important (Morgan et al., 2002). This draws the communicator away from the one-directional deficit model of communications (Bucchi, 2008) and towards a more dialogic model, where the perceptions of the nonexpert are not simply misconceptions to be adjusted but instead become concerns to be addressed through discussion and interaction. The approach allows researchers to assess not only what participants (both expert and non-expert) involved with an issue think but also why they think it (Kiker et al., 2005). This is valuable to expert and non-expert alike, as it allows both parties to fully express their perceptions of an issue and come to a greater understanding of the other party's perspective. The approach therefore allows the refinement of communication to focus on messages that are salient to both communicator and recipient, which will increase the efficacy and significance of these communications (Frewer, 2004).

\section{Applying the mental models method}

The mental models approach to risk (Morgan et al., 2002) is a mixed-method procedure which integrates aspects of Johnson-Laird's (1983) mental models theory with risk communication practice (Morgan et al., 2002). It assumes that the heuristics used by non-experts to interpret controversial, critical or unfamiliar issues do not form an entire model that directly reflects the world as the participant experiences it but rather constitute a series of interconnecting ideas that may colour the perception of an issue (Morgan et al., 2002). This qualitative and quantitative process consists of three main stages:

1. Qualitative semi-structured interviews are conducted one on one with a broad sample of the target population, as well as with technical experts in the field under question. These semi-structured interviews provide the participant with an opportunity to speak freely about the issue using their own terms or analogies, which can be examined in detail later as well as to discuss related or perhaps peripheral topics that the participant feels are 
relevant (Mabon et al., 2014). Once this stage is completed, a series of models are constructed which reflect the key perceptions held by each group and consider how these perceptions compare across groups of different "expertise".

2. A single quantitative questionnaire is constructed from the combined expert and non-expert models produced after the interview stage. This questionnaire tests whether the dominant perceptions that are highlighted by the model correctly represent the areas of greatest concern or interest that were expressed by the participants. The statements or questions are constructed using the language of the non-expert participants so as to minimise bias. The results of the questionnaire are then compared to the original models to test their validity in a larger sample.

3. If the model provides a good fit of the dominant perceptions of the target population, then a communication is designed that dovetails with the model content, in order to stimulate useful dialogue or provide information. This communication is tested for its ability to improve knowledge and understanding in the target population.

Whilst it is not unusual for users of the mental models approach to supplement their interviews with photos or drawings (Vosniadou and Brewer, 1992), two-dimensional images are not always a suitable inclusion when researching geoscience conceptions, as they rely on the participant employing a highly developed sense of spatial reasoning that some individuals struggle to use (Kastens and Ishikawa, 2006). Because geology is a very descriptive and visual science (Frodeman, 1995), this can lead to misinterpretation of ideas from both the expert and the non-expert. To address this issue, some previous studies of geological risk have employed 3D participatory modelling to provide an alternate method of elicitation during focus groups or interviews (Cadag and Gaillard, 2012). The inclusion of the 3-D model provided participants with a means to test their verbally expressed concepts in an alternative format. In this study, the approach of Morgan et al. (2002) was combined with a 3-D participatory model during the semi-structured interview stage. The use of a 3-D participatory component, whereby participants either use or create a 3-D model in the elicitation process, reflects the recognition that often participants in an interview may have difficulty expressing their thoughts verbally (Cooke and McDonald, 1986; Ongena and Dijkstra, 2007).

\section{Details of present research and research questions}

This study presented in this paper represents a part of broader research into what perceptions people hold about the geological subsurface. This research examined common ideas and attitudes to the subsurface with reference to how ex-

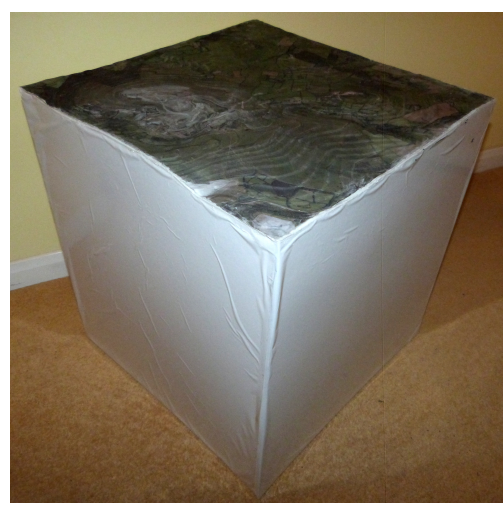

Figure 3. A blank 3-D participatory model used by both expert and non-expert participants during the semi-structured interviews to assist with non-verbal elicitation.

perts and non-experts conceptualise the geological subsurface. In particular, questions were addressed that included conceptualisation of the structure of the subsurface environment, the impact of human activity and the influence of natural forces or phenomena. The present analysis focuses on a subset of issues particularly relevant to hydrological interactions with the subsurface environment and the hazards that this might influence. Hydrological interactions with the subsurface were chosen as they were an unexpectedly ubiquitous theme identified in the non-expert interviews.

A combination of participatory, qualitative and quantitative methods was used. The 3-D model comprised a $1 \mathrm{~m} \times 1 \mathrm{~m} \times 1 \mathrm{~m}$ sized whiteboard cube, on the top surface of which was a topographically moulded aerial photo of each study location, an example of which is shown in Fig. 3. The aim was to enable participants to visually represent those concepts that related to the subsurface environment in their immediate vicinity.

Interviews were conducted by the primary researcher (H. Gibson) - a geologist with practical experience working as a formal and non-formal science communicator in a museum and national park. Care was taken by the researcher to limit bias during the interviews, and a conversational protocol (a relaxed back-and-forth conversational style) was employed during the interviews (Ongena and Dijkstra, 2007).

Three locations were selected for the purposes of the survey: one village in Cornwall and two villages in Devon. These villages had similar demographics - as assessed using the 2011 census data (Office of National Statistics, 2011) but different exposures to geology. The first village, Carharrack in Cornwall (population 1324), has a strong cultural and historical association with geology (abandoned former tin and copper mining) but little current geoscience activity in the immediate proximity. The second village, Sparkwell (including Hemerdon) in Devon (population 1246), has a moderate cultural and historical association with geology but has 
a prominent current geological industry active in the immediate vicinity (tungsten mine and aggregate quarries). The third village, Chulmleigh in Devon (population 1308), has neither a strong cultural and historical association nor a current geological presence; indeed the local geology is not particularly visible in the landscape.

The study incorporated both expert and non-expert interviews. Six interviews with experts (individuals with considerable experience either in the academic or industrial side of geology local to the area under survey) were conducted as well as a literature review of data relevant to a non-expert's understanding of the subsurface. After initial contact with parish councils was made to establish local awareness of the study and paper advertisements were placed in prominent locations around each village, non-expert participants were selected using a "snowball" method (Forrester, 2010). The snowball method of sampling occurs when you make contact with one or more members of your target population and ask them to introduce you to others who would potentially be interested in participating. It is a useful technique for reaching ambivalent or hard-to reach audiences (Forrester, 2010).

A total of 29 interviews were conducted across the three sites. As is described in the literature (Morgan et al., 2002; Mayer and Bruine de Bruin, 2014), the semi-structured interview questions were designed after an intensive literature review of the subject and supplemented by details from the expert interviews. The interviews were audio recorded and transcribed to ensure that the language of the participant was captured accurately. Interviews continued until a broad sample was achieved and repetition of concepts between participants occurred (Morgan et al., 2002). In line with the ethical approval granted by the University of Plymouth Science and Technology Ethical Committee, the names of all participants have been anonymised and replaced with factious names as is demonstrated in the results section. The interviews were conducted between January and September 2014. The questionnaire was designed after data collection and analysis of the interviews was completed and was constructed using the data gathered from the semi-structured interviews. The questionnaire was then distributed by post to all households (5214) in the target areas during September 2015 and was also made available online in the form of a link to the survey included with all postal surveys, with a total response rate of $228(4.37 \%)$ both online and through the mail. During the time of the initial interviews (January-March 2014) the UK was experiencing unusually severe winter storms that resulted in flood damage to key infrastructure across the southwest (e.g. disruption of main Devon-Cornwall rail line at Dawlish), and this high-profile flooding may have influenced the content of the interviews.

\section{Results: perceptions of the subsurface, water and geological hazards from 3-D drawings}

Participant responses to the semi-structured interviews were diverse and represented a wide range of opinions and perceptions. Although detailed mental modelling of the full set of responses is ongoing, an analysis of a subsection of the results allows some provisional observations to be made.

The main attention of the study was focused on the geological subsurface, so first this paper will provide context with some generalised results about the subsurface using the data collected with the 3-D participatory models. These models provided an insight into how people visualise the subsurface environment in their area and, in combination with the verbal results, provide an interesting idea of the perceptions of the subsurface the people in these three villages hold.

As experts and non-experts participated in interviews with the same structure and substance, their results can be directly contrasted to highlight similarities and differences. The images in Fig. 4 demonstrate some of the key concepts demonstrated by participants.

\subsection{General perceptions of the subsurface from 3-D model verbal explanations}

One of the initial observations was in the application of 3-D spatial reasoning by the geoscience experts. This is clearly visible in Fig. 4a and b, where both Eric and Edward utilised more than one side of the model in association, as well as making reference to the surface image for contextual cues. The use of 3-D spatial reasoning was common throughout the expert interviews, as this comment from Ethan indicates:

... so as you go down this could be all killas ${ }^{1}$, and could be cut off by ... by ... you've got lots of joints, so you have footwalls and hanging wall and slip planes. So you could find that down here, the further you go away from the hill, you find the granite's further away? (Ethan, geoscience expert)

This description includes an inherent use of 3-D spatial reasoning, demonstrated by Ethan in his inference of a change in location of the granite relative to the hill as influenced by the joints and slip planes. In general it was clear from the way that the experts used the block models that they were using 3-D spatial reasoning. There was a deliberate connection made between the adjacent sides of the model cube, and also with the surface topography and the aerial photograph. The experts completed the models with a great deal of gestural explanation (Kastens et al., 2008), even to the extent of using the pens provided for annotation to demonstrate a fault structure present in the area (visible in Fig. 4b). This 3-D spatial reasoning was not, however, present to the

\footnotetext{
${ }^{1}$ A regional term for Devonian-Carboniferous low-grade phyllite (Kearey, 1996).
} 

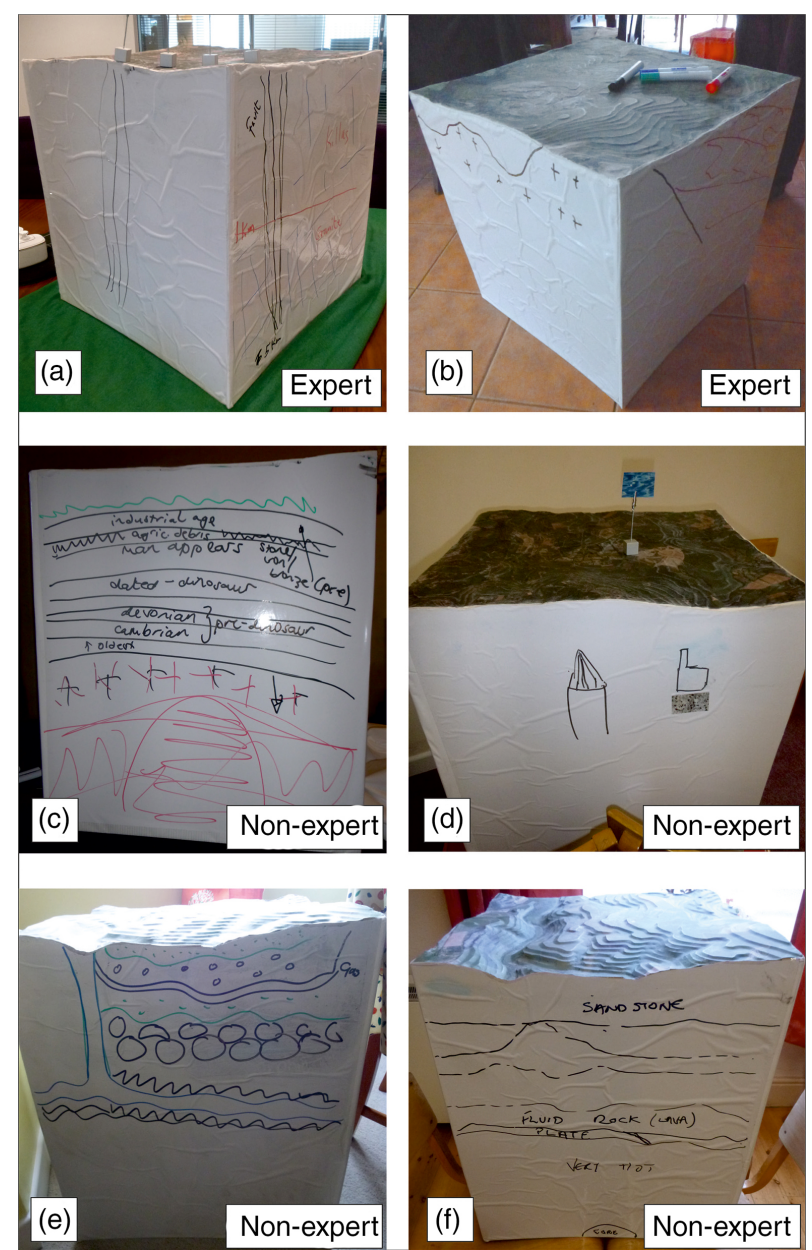

Figure 4. Images of 3-D participatory models completed by expert and non-expert participants. (a) Eric - an expert participant - represents the expert model, with a logical diagram utilising more than one side of the model (including the surface), with detail provided by numerical and factual annotation. (b) Edward - an expert participant - also demonstrates an expert model, with a representation of a fault structure displayed at the surface and symbols used to identify different rock types. (c) Kimberley - a non-expert participant from Carharrack - conceives the subsurface in a couple of interesting ways. Firstly, the red shading is used to depict the Earth's core, initially as a semi-circular shape and then later modified to match the linear appearance of the rest of the diagram. In addition, the diagram shows some uncertainty about the inferred ground level, which is drawn with a green zigzag line, below the actual surface of the model. (d) Katie - a non-expert participant from Carharrack presents a much sparser diagram, with subterranean buildings emphasising the human interaction with subsurface space. (e) Charlotte - a non-expert participant from Chulmleigh - drew a direct link between the surface and the subsurface in the form of a channel that connects the topographic low (where the river is shown on the aerial photograph) and an underground body of water, which cuts across the entire model. Finally, (f) Charles - a non-expert participant from Chulmleigh - shows another model which has been interpreted to represent a more scientific model, with the Earth's core represented at the bottom and the different layers as approximations of different scales of geological concepts, from tectonic plates to erosional surfaces of sandstone. same degree in the non-expert participants. Some spatial reasoning was used, but it was most often utilised in a purely geographic two-dimensional way. Moreover, all of the nonexperts limited their elicitation to a single side of the model cube.

I'm surprised really that [the quarry] is in a quite high part compared with others. As you move down here [from the mine site], I know from my own experience, as you come south ... the rocks are actually a bit softer. (Henry, Hemerdon and Sparkwell resident)

The models also demonstrated another consistent difference between the experts and the non-experts, and that was an anthropocentric, or human-focused, view of the subsurface (Slovic, 2010). For the expert participants, a concept of the geology came first, which stimulated concepts related to the mining; however, for the non-experts it appeared that the mining (or other types of human interaction) was a concept that came first and only provided an indicator to the geology subsequent to that human interaction. This anthropocentric perspective of the subsurface is demonstrated in Fig. 4d, which also indicates how some participants who held a strongly anthropocentric model had a great deal of difficulty in adding any other detail to their expressed perception of the subsurface.

Q: So, if you were to, like, dig straight down now, what would you come across?

A: I don't know. I don't want to know ... There could be things underneath the ground like that kind of thing ... Other houses; I don't know. (Katie, Carharrack resident)

Perceptions shaped around human concerns contrast with the more expected conventional geological depiction of subsurface relations (e.g. Fig. 4c). These types of diagram (called "scientific" from here on) varied in the level of detail provided, with some (Fig. 4c) being very detailed and exhibiting a large amount of additional annotation relating to dates and eras, both historical and geological. These nonexpert scientific models focus attention on a range of themes. Some participants, for example as shown in Fig. 4c and f, focus very strongly on the centre of the Earth. In Fig. 4f the focus was more specifically related to the types of layers one might encounter if penetrating the subsurface but also included a visual link to the Earth's core, which was identified early in the construction of the diagram. The role and importance of underground water was also indicated in the way that participants depicted the subsurface, such as with rounded pebbles.

A key point emerging from the semi-structured interviews was a strong disassociation among non-experts between the subsurface and surface environments. This is most evident in Fig. 4c, where despite the top of the cube being a representation of the topography, and the respondent being asked 


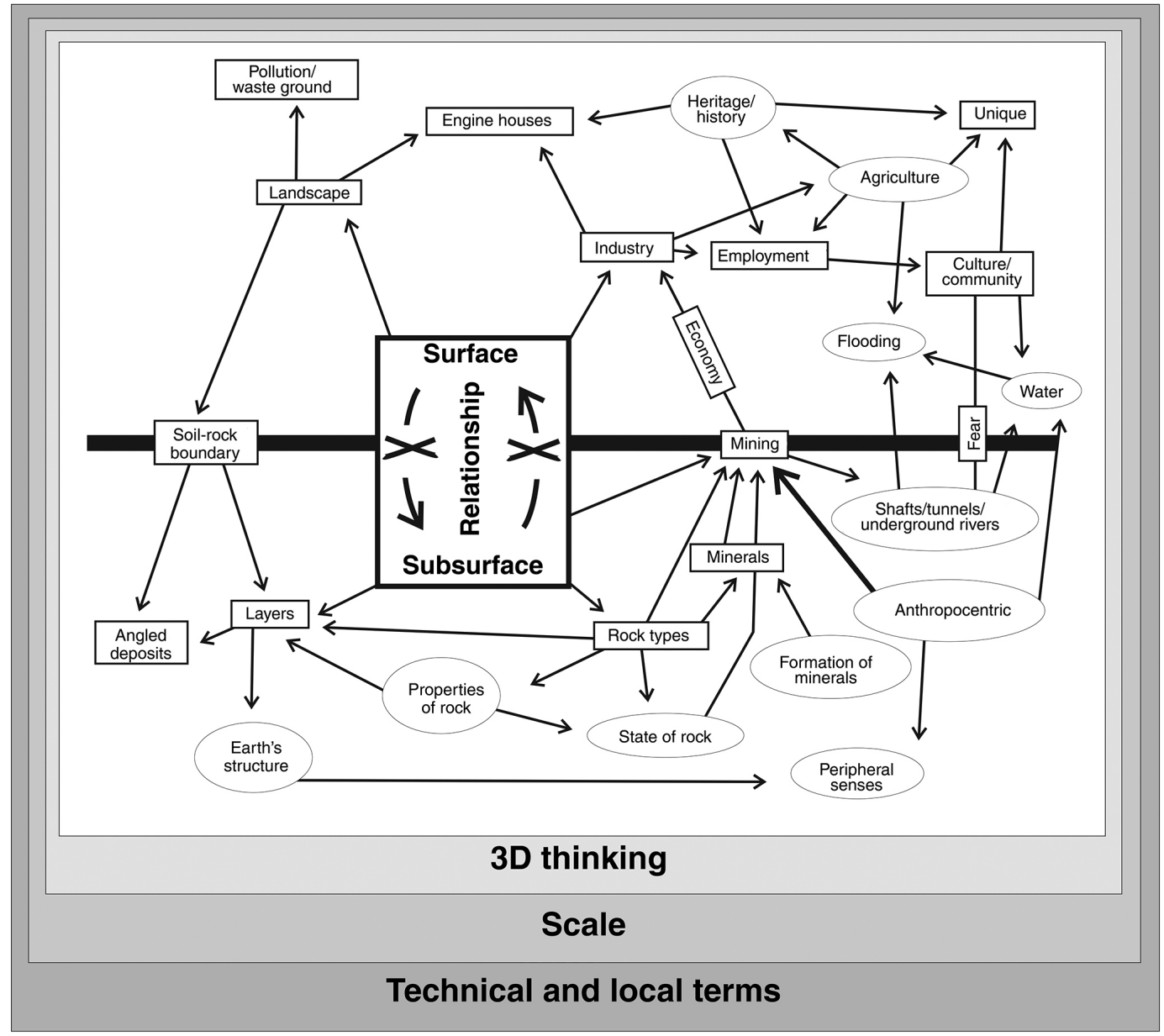

Figure 5. A mental model of expert and non-expert perceptions of the subsurface in the south-west of England. Rectangular nodes are those shared between experts and non-experts; oval nodes are those expressed by non-experts alone. The three frames " 3 -D thinking", "scale" and "technical and local terms" have been placed externally as they provide context for all of the other nodes.

to present what she thought was "directly beneath her", an artificial ground surface was added to the side of the cube. This disconnection was demonstrated in multiple model depictions and, alongside the limited use of 3-D spatial reasoning, is a strong discriminator between the non-experts and the experts.

When a connection between the surface and subsurface was presented by non-experts, it was frequently vague and portrayed in a general sense that was more related to the nature of the rock in the area, as is evident in the following quote:

But granite, I would have thought, [is] just about everywhere, really. I don't know what depth that would be. It's probably near the surface, but I would have thought there would be granite around.

(Katrina, Carharrack resident)

In this example, the existence of a particular rock type was not consciously linked with any visible landscape feature. In contrast, the remarks below highlight an expert connecting a mapped unit of geology below with a specific landscape feature above, and using the observable outcrops as cues to discern the underlying differences in local geology.

\begin{abstract}
Well perhaps it's not the same sandstone for a start; you can make a measurement of one sandstone in one hill there and then you know it's dipping towards the hill ... towards us, because that sandstone is all the same. (Edgar, geoscience expert)
\end{abstract}

\subsection{Combined mental model}

By integrating the findings of experts and non-experts from the three study areas, a final combined mental model has been obtained (Fig. 5). This model represents a collective view of the public perception of the geological subsurface, especially focusing on the interaction between surface and subsurface elements in this conception. The central feature is the connection between the surface and the subsurface. Most 
'Water naturally forms channels underground in order to flow through rock'

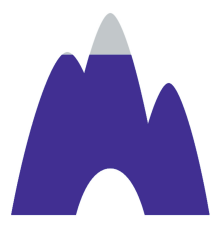

$78.9 \%$ agree

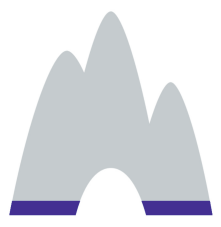

$6.7 \%$ disagree

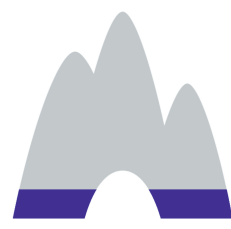

$14.3 \%$ don't know

Figure 6. Attitudes of questionnaire respondents $(n=223)$ to the statement "water naturally forms channels underground in order to flow through rock".

participants alluded to some degree of linkage, but it was the expert participants who consistently used this connection in constructing their subsurface model. This difference between the experts and the non-experts was also present in other shared nodes, such as "layers" and the "soil-rock boundary", but of particular interest to this study is the emphasis from the non-experts on the nodes of "water" and "flooding".

\section{Detailed analysis of themes relevant to hydrology and hazard}

To explore the usefulness of this model for applied geoscience in general and geohazards in particular, this section examines in more detail the two non-expert nodes in Fig. 5: water and flooding. These nodes potentially offer an interesting insight into the general perceptions of the non-experts into the geological subsurface.

\subsection{Underground rivers}

Firstly, although water was mentioned by the expert participants, it was very much a peripheral concept, as is shown in this reference to mining activities.

We'll have to satisfy the Mines Inspectorate that what we are doing is safe and won't result in potential mine flooding. So ... I don't know, I suspect that the ... presence of those mine workings would be a nuisance if we drilled into them, so we have to avoid them from that point of view, but [they] potentially represent quite a good ... water source for us. (Eric, geoscience expert)

For the non-experts, however, the presence and movement of water was frequently mentioned, most prominently in the recurring notion of underground rivers.

I think you'd find a lot of water, and I imagine there would be lots of channels. 'Cos I think the water would have to seep into the ground and it has to run down 'cos we are so high that I think there would be an underground network of holes or natural sewers ... Just because of the pure volume of water that we have, and we don't flood as much so there might be some kind of water table that bits of land, kind of, not floating on top but almost like resting on top. (Christian, Chulmleigh resident)

I think water, if you go down, there's ... you know ... water would come off of different bits, different directions and little bits, a bit like underground streams really, but then finally I think you'd get these solid stones where there's nothing there really. (Charlotte, Chulmleigh resident)

Well, I think water, you know, the amount of rain that we've had, you know, over the last couple of years especially, it's not better for this area ... [Laughter] ... because it gets into these tunnels sometimes I think and then it ... just got nowhere to go. (Kim, Carharrack resident)

So I imagine that the top ... the top sort of surface ... would be 15 feet, and then you would get into a granite and that would be ... I don't know how far down then. That would go on down, and I imagine that in that there are waterways and underground streams and that sort of thing ... going through the granite. (Howard, Hemerdon and Sparkwell resident)

The perception of the existence of underground rivers as the principal pathway for water to move in the geological subsurface was so common that one of the questions in the subsequent questionnaire was dedicated to it. Questionnaire recipients were asked how much they agree with the statement "water naturally forms channels underground in order to flow through rock". The majority of respondents $(78.9 \%)$ chose to either agree or strongly agree (Fig. 6), showing how prevalent this perception was amongst the questionnaire sample population.

This misconception of subsurface water routeways also appeared to relate to the permeability of different rock types. Some types of rock seemed to be perceived as allowing water to pass through them more easily, but other types of material such as clay were more of a barrier.

But a lot of it must be broken killas underneath because it - water - literally drains, disappears. You don't get waterlogged ground generally in this area, you know. (Kenneth, Carharrack resident)

So there is water under us here which I suppose has been formed or collected in certain layers - or runs through certain geological layers. But right under this house - or under Chulmleigh - I couldn't tell whether we were built on rock or what sort 
of strata, to be honest. There's a lot of stone, I wouldn't have thought it's granite, but it could be. (Christopher, Chulmleigh resident)

\subsection{Water moving through rocks}

Some participants also attempted to explain how water does move through rocks, with particularly descriptive techniques.

I think it filters through the rock. Yeah, I think it does. It comes down like rain through rock, doesn't it? And as long as they're pumping, then they've got a dry place to work, but it will come up as it did until the mine floods. And I think it will flood almost to surface, as far as I remember. (Kara, Carharrack resident)

When this notion of the permeability of rocks was posed in the questionnaire as "Water cannot flow through solid rock" (Fig. 7), the just over half of respondents answered the question incorrectly, choosing either the wrong answer $(28.6 \%)$ or "I don't know" (21.8\%). Whilst $49.5 \%$ answered the question correctly, agreeing that water could pass through solid rock, many added an additional note to the question specifying different types of rock that would influence their perception. This suggests that a large number of participants are uncertain about the properties of subsurface hydrology.

\subsection{Water and instability}

Another common concern expressed by participants was that presence of water in the subsurface would result in instability and possibly cause ground failure or collapse. This notion was expressed differently in the different locations. In Carharrack, for example, the sense of instability was strongly connected to the historical mining heritage present in the area.

It's a different kettle of fish, mind you, those sinkholes, but I'm wondering if a lot of rain is seeping into old mine workings and might make them sink. (Kevin, Carharrack resident)

In Hemerdon and Sparkwell, in contrast, concern was expressed for the impact of new mining activity on existing hydrological environments.

You can't keep digging up what's underneath you. It alters things. It alters the landscape. It alters what comes out of the ground. It alters the water table. (Hannah, Hemerdon and Sparkwell resident)

For the experts, this connection between geology and flooding had been a fairly logical one, but, in general, nonexpert participants did not consider this issue a geological link. Instead, most believed that the flooding had a superficial cause and it was connected to human activity on the floodplains.
'Water cannot flow through solid rock'

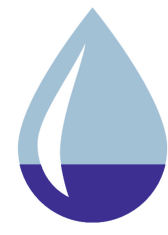

$28.6 \%$ agree

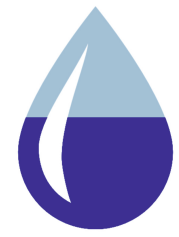

$49.5 \%$ disagree

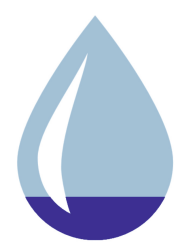

$21.8 \%$ don't know
Figure 7. Attitudes of questionnaire respondents $(n=220)$ to the statement "water cannot flow through solid rock".

Q: Can you think of anything you've seen to do with geology in the news recently?

A: No, except ... um ... and this is a bit broad, the flooding in the Somerset Levels and that's not ... really ... to do with that [geology]. (Christie, Chulmleigh resident)

So much of things I think of relate to geography I suppose, whether it's flooding in Bangladesh or India or China you know, so it's more geography related rather than geology. I'm not sure it contributes. (Heather, Hemerdon and Sparkwell resident)

I know you have to progress [with new mining development]. To what end, though? Because you can keep progressing, and now look at us. We're getting all this flooding. (Hannah, Hemerdon and Sparkwell resident)

Although attitudes to flooding and ground instability caused by the presence of water were not investigated directly, the evidence from the qualitative interviews provides interesting inferences. The non-expert misconception of underground rivers was not anticipated at the outset of the research, although it could possibly be expected from anecdotal experience (Kasperson et al., 1988). Common misconceptions like the prevalence of underground rivers expose deeper issues, such as the public's understanding of how water moves through subsurface environment and how water in the subsurface can impact ground stability (Thomas et al., 2015).

Although this study indicates the conceptual gap that exists between experts and non-experts in the context of the geological subsurface, particularly subsurface hydrology, this type of study also provides useful context for communicators. For one thing, the qualitative interviews themselves show the value that the public place on gaining new and more detailed information that will allow them to continue to make effective decisions about our changing environment. This was highlighted by questions raised by participants in connection to the recent flooding events, which seemed to 
show that current events had produced an opportunity for communication that was not present previously.

And actually, I have to say the Somerset Levels recently have made me think a lot more about the geology and how they flood and how we build on floodplains. We're taking no notice of what's underneath and whether anything can drain away. So, I think it would be much more important to all of us soon. (Kimberley, Carharrack resident)

\section{Discussion and conclusion}

As well as "making public" misconceived ideas about how the natural world works, mental models can expose nonexpert perceptions that are so outlandish that the expert might never have considered them. In the following statement, a non-expert links news stories he has heard about earthquakes and fracking with resource extraction.

It does concern me a bit sometimes the number of major earthquakes we seem to be getting around the Pacific. I'm wondering why. Is it something we're doing to the world that's causing this? I don't think its fracking because they aren't fracking there. Maybe because they're taking oil out of the ground and it's releasing pressure so that the world plates can move about a bit more. I don't know. (Hugh, Hemerdon and Sparkwell resident)

Beyond the occasional ability to expose fairly perverse misconceptions about the Earth's systems, the mental models approach provides valuable context for geoscience communicators. Its main benefit lies in bringing to light alternative scenarios that are central to the way some participants analyse the processes that operate beneath their feet. In this regard, the heightened "anthropocentric view" is an important perspective, and one that has been recognised previously. Lave and Lave (1991), for example, found in a similar study that some participants would orientate their whole perception of past and future flood events on the fact that they were "human-made". Not appreciating the geological aspects of flooding may mean that people conceive an inaccurate view of local flooding threat (e.g. from rising groundwater levels).

Ordinary people's anthropocentric depiction of the subsurface is likely to have been overlooked by communicators; certainly it is not present in the expert interviews in any noticeable way. It is revealed because the mental models method establishes direct comparisons of expert and nonexpert perceptions on the same issue. Such inter-comparisons highlight fundamental mismatches of thinking, such as the use of 3-D spatial reasoning and the logical connection between the surface and the subsurface. They also shed light on the reasoning behind misconceptions, such as the ubiquitous popular references to underground rivers, and offer up addi- tional nuanced detail to communicators attempting to grasp the public viewpoint.

Through mental models, geoscientists can be armed with empirical, detailed and generalised data of perceptions surrounding an issue, as well as being aware of unexpected outliers in perception that they may not have considered relevant but which nevertheless may locally influence communication. Using this approach, researchers and communicators can develop information messages that more directly engage local concerns and create open engagement pathways based on dialogue, which in turn allow both groups to come together and understand each other more effectively. Given the ongoing wider challenges in geoscience communication - especially in contested subsurface interventions associated with shale gas extraction, carbon capture and storage and radioactive waste disposal - the ability for geo-communicators to be more carefully attuned to how individuals and communities think will become increasingly tested.

Author contributions. Hazel Gibson, Iain S. Stewart and Sabine Pahl designed the survey protocols and interview questions. Hazel Gibson conducted all interviews and completed primary analysis and construction of the mental model. Alison Stokes and Sabine Pahl assisted with secondary analysis of data and construction of the mental model. Iain S. Stewart assisted with construction of the mental model. Hazel Gibson designed the questionnaire with assistance from Sabine Pahl, Iain S. Stewart and Alison Stokes. Hazel Gibson prepared the manuscript with assistance from all co-authors.

Acknowledgements. This work was supported by the Natural Environment Research Council (Quota Award number 1222755). The authors would like to thank Mark Anderson for his assistance and supervision during this research. The authors would also like to acknowledge the valuable support of Robert Collier, School of Marine Science and Engineering, Plymouth University, for his assistance in the construction of the 3-D participatory models.

Edited by: S. Illingworth

\section{References}

Barclay, J., Haynes, K., Mitchell, T., Solana, C., Teeuw, R., Darnell, A., Crosweller, H. S., Cole, P., Pyle, D., and Lowe, C.: Framing volcanic risk communication within disaster risk reduction: finding ways for the social and physical sciences to work together, Geol. Soc. Lond. Spec. Publ., 305, 163-177, 2008.

Bucchi, M.: Of deficits, deviations and dialogues: Theories of public communication of science, Handbook of public communication of science and technology, Routledge, Oxon, 57-76, 2008.

Cadag, J. R. D. and Gaillard, J. C.: Integrating knowledge and actions in disaster risk reduction: the contribution of participatory mapping, Area, 44, 100-109, doi:10.1111/j.14754762.2011.01065.x, 2012. 
Callon, M.: The role of lay people in the production and dissemination of scientific knowledge, Sci. Technol. Soc., 4, 81-94, 1999.

Cooke, N. M. and McDonald, J. E.: A formal methodology for acquiring and representing expert knowledge, Proc. IEEE, 74, 1422-1430, 1986.

Donovan, K.: Doing social volcanology: exploring volcanic culture in Indonesia, Area, 42, 117-126, 2010.

Donovan, K., Suryanto, A., and Utami, P.: Mapping cultural vulnerability in volcanic regions: The practical application of social volcanology at Mt Merapi, Indonesia, Environ. Hazards, 11, 303-323, 2012.

Evans, J. S. B.: Logic and human reasoning: an assessment of the deduction paradigm, Psycholog. Bull., 128, 978-996, 2002.

Eysenck, M. W. and Keane, M. T.: Cognitive psychology: A student's handbook, 6th Edn., Taylor and Francis (Psychology Press), East Sussex, 2010.

Fischhoff, B.: Risk perception and communication unplugged: twenty years of process, Risk analysis, 15, 137-145, 1995.

Forrester, M. A.: Doing qualitative research in psychology: A practical guide, Sage, London, 2010.

Frewer, L.: The public and effective risk communication, Toxicol. Lett., 149, 391-397, 2004.

Frodeman, R.: Geological reasoning: Geology as an interpretive and historical science, Geol. Soc. Am. Bull., 107, 960-968, 1995.

Gilovich, T., Griffin, D., and Kahneman, D.: Heuristics and biases: The psychology of intuitive judgment, Cambridge University Press, Cambridge, England, 2002.

Goel, V.: Anatomy of deductive reasoning, Trends Cognit. Sci., 11, 435-441, 2007.

Johnson, M. S.: Public participation and perceptions of watershed modeling, Soc. Nat. Resour., 22, 79-87, 2008.

Johnson-Laird, P. N.: Mental models in cognitive science, Cognit. Sci., 4, 71-115, 1980.

Johnson-Laird, P. N.: Mental models: Towards a cognitive science of language, inference, and consciousness, Harvard University Press, Cambridge, Massachusetts, 1983.

Johnson-Laird, P. N.: Mental models and cognitive change, J. Cognit. Psychol., 25, 131-138, doi:10.1080/20445911.2012.759935, 2013.

Kasperson, R. E., Renn, O., Slovic, P., Brown, H. S., Emel, J., Goble, R., Kasperson, J. X., and Ratick, S.: The social amplification of risk: A conceptual framework, Risk Analy., 8, 177-187, 1988.

Kastens, K. A. and Ishikawa, T.: Spatial thinking in the geosciences and cognitive sciences: A cross-disciplinary look at the intersection of the two fields, Geol. Soc. Am. Spec. Papers, 413, 53, 2006.

Kastens, K. A., Agrawal, S., and Liben, L. S.: Research methodologies in science education: The role of gestures in geoscience teaching and learning, J. Geosci. Educ., 56, 362-368, 2008.

Kearey, P.: The new Penguin dictionary of geology, Penguin Books, 1996.

Keller, C., Siegrist, M., and Gutscher, H.: The role of the affect and availability heuristics in risk communication, Risk Analysis, 26, 631-639, 2006.

Kiker, G. A., Bridges, T. S., Varghese, A., Seager, T. P., and Linkov, I.: Application of multicriteria decision analysis in environmental decision making, Integr. Environ. Assess. Mange., 1, 95-108, 2005.
Kunreuther, H. and Slovic, P.: Science, values, and risk, Annals of the American Academy of Political and Social Science, Chal. Risk Assess. Risk Manage., 545, 116-125, 1996.

Lane, S., Odoni, N., Landström, C., Whatmore, S., Ward, N., and Bradley, S.: Doing flood risk science differently: an experiment in radical scientific method, T. Inst. Brit. Geogr., 36, 15-36, 2011.

Larson, K. G., Long, G. R., and Briggs, M. W.: Periodic properties and inquiry: Student mental models observed during a periodic table puzzle activity, J. Chem. Educ., 89, 1491-1498, 2012.

Lave, T. R. and Lave, L. B.: Public perception of the risks of floods: Implications for communication, Risk Analysis, 11, 255-267, 1991.

Leiserowitz, A.: Climate change risk perception and policy preferences: The role of affect, imagery, and values, Climatic Change, 77, 45-72, 2006.

Liverman, D.: Communicating geological hazards: educating, training and assisting geoscientists in communication skills, Springer, the Netherlands, 41-55, 2010.

Mabon, L., Shackley, S., and Bower-Bir, N.: Perceptions of sub-seabed carbon dioxide storage in Scotland and implications for policy: A qualitative study, Mar. Policy, 45, 9-15, doi:10.1016/j.marpol.2013.11.011, 2014.

Maceda, E. A., Gaillard, J.-C., Stasiak, E., Le Masson, V., and Le Berre, I.: Experimental use of participatory 3-dimensional models in island community-based disaster risk management, Shima, 3, 72-84, 2009.

Mayer, L. A. and Bruine de Bruin, W.: The 'Mental Models' Methodology for Developing Communications, in: Effective Risk Communication, edited by: Arvai, J. and Rivers III, L., Routledge, Oxon, 165-189, 2014.

Mileti, D., Nathe, S., Gori, P., Greene, M., and Lemersal, E.: Public hazards communication and education: the state of the art, Natural Hazards Center University of Colorado, Institute of Behavioral Science, University of Colorado, Boulder, 2004.

Morgan, M. G., Fischoff, B., Bostrom, A., and Atman, C.: Risk communication: A mental models approach, Cambridge University Press, New York, 2002.

Nisbet, M. C.: Communicating climate change: Why frames matter for public engagement, Environment: Sci. Policy Sustain. Dev., $51,12-23,2009$.

Office for National Statistics: 2011 Census: Aggregate data (England and Wales), UK Data Service Census Support, downloaded from: http://infuse.ukdataservice.ac.uk, 2011.

Ongena, Y. P. and Dijkstra, W.: A model of cognitive processes and conversational principles in survey interview interaction, Appl. Cognit. Psychol., 21, 145-163, 2007.

Over, D. E.: New paradigm psychology of reasoning, Thinking and Reasoning, 15, 431-438, 2009.

Panagiotaki, G., Nobes, G., and Potton, A.: Mental models and other misconceptions in children's understanding of the earth, J. Exp. Child Psychol., 104, 52-67, 2009.

Rosenbaum, M. S. and Culshaw, M. G.: Communicating the risks arising from geohazards, J. Roy. Stat. Soc. A, 166, 261-270, 2003.

Shackley, S., McLachlan, C., and Gough, C.: The public perception of carbon dioxide capture and storage in the UK: results from focus groups and a survey, Climate Policy, 4, 377-398, 2004. 
Skarlatidou, A., Cheng, T., and Haklay, M.: What Do Lay People Want to Know About the Disposal of Nuclear Waste? A Mental Model Approach to the Design and Development of an Online Risk Communication, Risk Analysis, 32, 1496-1511, doi:10.1111/j.1539-6924.2011.01773.x, 2012.

Slovic, P.: Perception of risk, Science, 236, 280-285, 1987.

Slovic, P.: The feeling of risk: New perspectives on risk perception, Routledge, Oxon, 2010.

Slovic, P., Finucane, M. L., Peters, E., and MacGregor, D. G.: Risk as analysis and risk as feelings: Some thoughts about affect, reason, risk, and rationality, Risk Analysis, 24, 311-322, 2004.

Slovic, P., Finucane, M. L., Peters, E., and MacGregor, D. G.: The affect heuristic, Eur. J. Operat. Res., 177, 1333-1352, 2007.

Sturgis, P. and Allum, N.: Science in society: re-evaluating the deficit model of public attitudes, Publ. Underst. Sci., 13, 55-74, 2004.
Thomas, M., Pidgeon, N., Whitmarsh, L., and Ballinger, R.: Mental models of sea-level change: A mixed methods analysis on the Severn Estuary, UK, Global Environ. Change, 33, 71-82, 2015.

Vari, A.: The Mental Models Approach To Risk Research-An RWM Perspective, Radioactive Waste Management Committee, OECD Nuclear Energy Agency: Moulineaux, France, 2004.

Vosniadou, S. and Brewer, W. F.: Mental models of the earth: A study of conceptual change in childhood, Cognit. Psychol., 24, 535-585, 1992.

Wagner, K.: Mental models of flash floods and landslides, Risk Analysis, 27, 671-682, 2007.

Wallquist, L., Visschers, V. H., and Siegrist, M.: Impact of knowledge and misconceptions on benefit and risk perception of CCS, Environ. Sci. Technol., 44, 6557-6562, 2010.

Wynne, B.: Knowledges in context, Science, technology, and human values, 16, 111-121, 1991. 